\title{
Near-Death Experiences in a Pacific Northwest American Population: The Evergreen Study
}

\author{
James H. Lindley \\ Sethyn Bryan \\ Bob Conley \\ The Evergreen State College \\ Olympia, Washington
}

To the Memory of John Lennon

\section{INTRODUCTION}

With the refinement of modern resuscitation procedures increasing numbers of people have "died" and then returned to life. Many individuals report that during the time of clinical death extraordinary phenomena occur, which challenge accepted ideas of what happens when we die. A remarkable degree of correlation in these reports demands serious consideration. This paper will address pertinent questions raised by these reports.

This study seemed needed for five reasons: 1) Increasing numbers of responsible people report that during the time of clinical death they maintained conscious awareness of both external and internal environments. 2) The definition of death may need to be adjusted in light of these experiences. 3) The question of whether the NDE is a separate state of consciousness or the result of patterned hallucinations needs to be studied. 4) These experiences may be the source of much of humanity's religious belief and of the persistent, crosscultural belief in an afterlife. 5) Much popular literature proclaims that these experiences are proof of an afterlife. This claim is obviously premature. Before such issues can even be addressed, these experiences must be subjected to objective, scientific studies. The phenomenon is too important to be abandoned to the pulp writers.

Because of time constraints on our research our criteria for inclu- 
sion in this study were simply that a person had been in a lifethreatening situation and felt he had actually died. It quickly became apparent, however, that we would not be taking our sample from the ranks of the uninformed. The "contamination" of the near-death population is widespread due to the success of books by researchers such as Moody (1975) and Ring (1980). Put more positively, experiencers are more willing to come forward now that the threat of ridicule has lessened. Nevertheless, we took into account that many of our respondents had been exposed to near-death literature since their own encounter with death. Understandably, this awareness could have affected the manner in which an individual interpreted the basic experience.

Despite these limitations, our respondents' experiences did tend to fall into a common pattern marked by five distinct stages which we shall briefly summarize below. These stages have been outlined previously by both Moody (1975) and Ring (1980). It is important to note that all these stages are not perceived by everyone and that they are not necessarily consecutive levels of experience. Furthermore, not everyone who comes close to death has a near-death-type experience.

The first stage of the near-death experience is one of overwhelming peace in which all agony ceases. There is a feeling of unequalled calm and acceptance. Apparently, from our reports, the further one "sinks" into death the deeper this sense of well-being becomes.

The second stage is characterized by a sense of separation from the body. At this point, awareness shifts from being identified with the physical body and is described as being similar to the view of the eye of a camera. It may also appear that the consciousness is enclosed within a second body similar to but distinct from the physical one.

In the third stage the individual finds himself moving within a dark void or traveling down a long tunnel.

During the fourth stage a light is encountered that is almost always described as being either white or golden and of indescribable brilliance. The fifth stage has been labeled "entering the light" by both Moody and Ring. We found this phrase to be misleading since it implies experiencers first encounter the light and then enter it. Within this light they apparently discover "worlds" from which the light has its origin. We did not have a single report that described the light as emanating from a non-physical environment. Though brightly illuminated, these non-physical environments seemed distinct from the brilliant light of the fourth stage. In fact, we were more inclined to regard these "worlds" as having their origin within the light. In this report, we shall refer to the fifth stage, then, as "the inner 
setting." The setting is usually a location of great natural beauty such as a garden, valley, or meadow. Here the experiencer spends time before deciding to return.

In this report we shall outline our methods, findings, and conclusions along with suggestions for further research. We shall also compare and contrast our study with Ring's investigation.

\section{METHOD}

At the beginning of our study we decided to advertise for people "who have been clinically dead or feel they have died and returned to life." We realized the basic weakness in such a procedure, but we calculated that only in this way could we gain a significant number of people in the five months we had to complete the project. Obviously, we cannot claim to have a representative, random sample of Americans from the Northwest. We do think, however, that the cases gathered demonstrate a reasonable degree of comparability to Ring's (1980) study.

In our first advertisement we did not mention we were seeking people who had had near-death experiences, only that we sought people who had come close to death. We did not offer payment. We extended assurances of complete confidentiality and our subjects signed a consent form advising them of our project intent. Later, interest in our research from radio, television, and newspapers allowed us to reach larger numbers of people but it also compelled us to be more open that we were studying the near-death experience. We do not think this significantly altered the quality of our respondents, though, because public awareness of this phenomenon is already high.

A total of 49 people were interviewed, who described a total of 55 encounters with death. Of these, 35 were contacted via some form of advertising and 14 were obtained by word of mouth. We also declined interviews with another 20 contacts who did not meet the criterion of having been clinically dead or of feeling very strongly they had died.

Due to time considerations, we were unable to confirm the actual clinical deaths of our subjects although we have kept records of when and where they died, whenever possible, for future follow-up.

The interviews were all tape recorded and were generally conducted at the home of the respondent, although some were made over the phone when the person lived a great distance from our facilities. During the interview we allowed the subject to give us an uninterrupted account of his encounter with death. After the narra- 
tive was completed, we followed with a series of standard questions (Ring, 1980) that probed for details on the nature of his experience and the effect it had on his life. We also gathered demographic information for use in analyzing the results.

Upon completion of the interview, we informed our respondents we would notify them of our results and offered them a copy of our project report.

We used a rating system described elsewhere (Ring, 1980) to isolate and evaluate specific qualities of the experience. In order to determine when a particular quality was present, we each listened separately to the taped interview and recorded our decision on a rating form. Only if two out of three raters agreed did we assume a characteristic was present.

\section{RESULTS}

The most intriguing aspect, indeed the crux of the near-death experience, is its invariance across broad social lines. As one listens to personal reports of those who have come close to death, one is struck not by the differences but by the similarities of description. To demonstrate this point we shall move through the five stages of the near-death experience and compare our findings with Ring's.

First Stage. Feelings of peace, warmth, and well-being are the overwhelming sensations reported. As one woman who was a drowning victim described it:

I was in agony ... and then all of a sudden I became very warm and I was floating, I felt very good and all the pain was just gone instantly! (6)

Another woman (9), who had almost died as the result of a hemorrhage while she was a child, said she "felt guilty" because the sensations she was experiencing felt so good.

Words commonly used to describe this stage are "peace," "happiness," "painlessness," and "tranquility." It is unnecessary to quote further descriptions of the first stage since they have been amply documented by Ring and others. In fact, it is often exhausting to listen to these accounts of sheer bliss because they are so predictable. In our study, 41 of 55 near-death encounters contained some element of peace. This means $\mathbf{7 4 . 5}$ percent of our sample had entered the first stage of death. Ring found 60 percent of his respondents had experienced the first stage. It should be noted that Ring's sample was much larger than ours, with a total of 104 near-death encounters and his overall percentage of near-death experiencers (48 percent) was much lower than ours. (See Table 1 for comparative graph.) 
APPENDIX
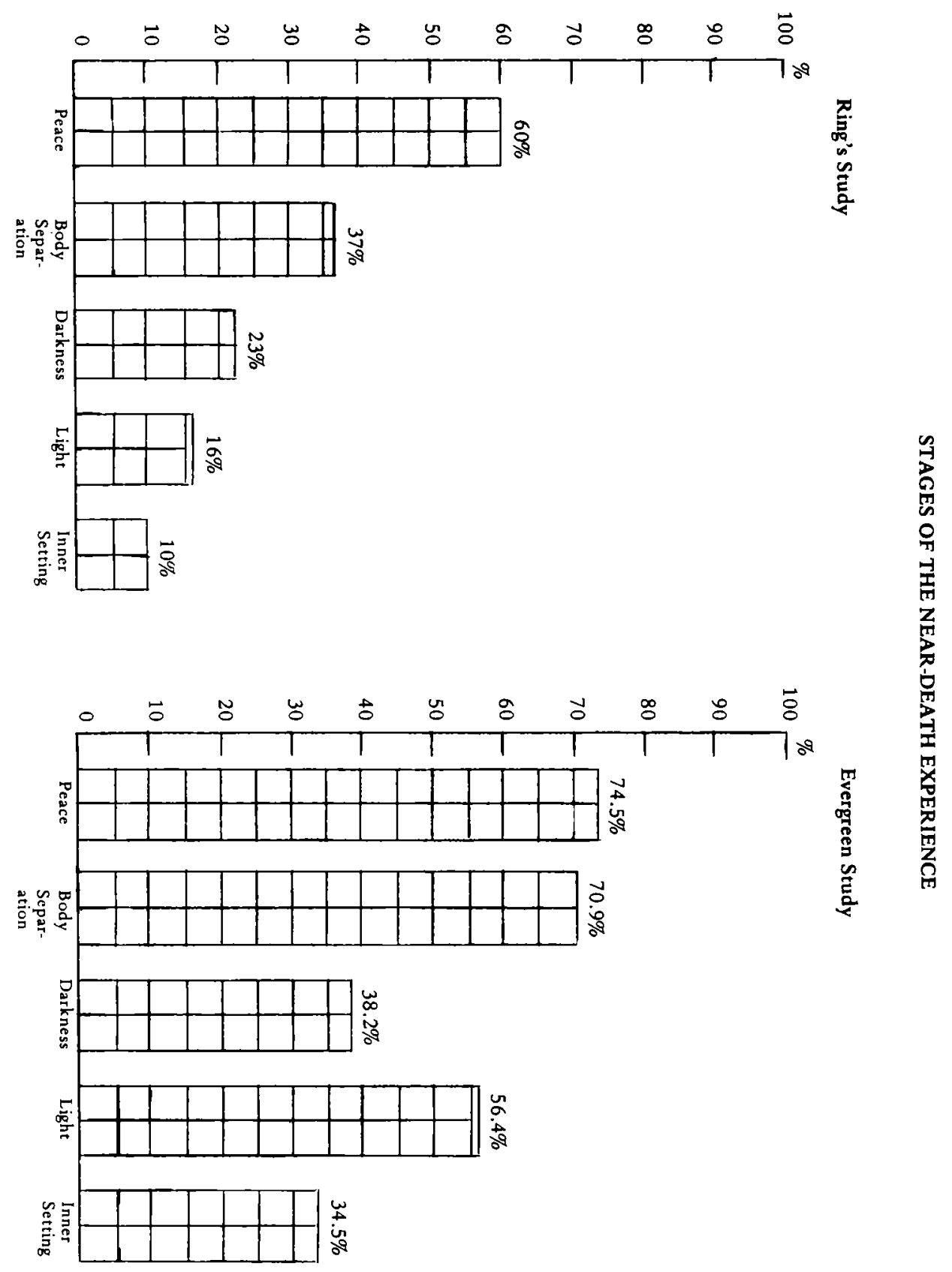
Second Stage. Here the near-death phenomenon begins to display qualities that challenge conventional theories of mind. People report that during this time their awareness separates from their physical body and moves spontaneously about the external environment. It may also travel at incredible rates of speed into unrecognized areas of consciousness. Taken at face value, this stage indicates consciousness is capable of existing without the body.

My next awareness was floating in the air about 5 feet above the end of the hospital bed. I saw a body in the bed, it looked awful, a greenish-gray color . . . it looked dead. Nurses and doctors were working on the body. A nurse was yelling a coded message over the intercom ... it dawned on me that maybe it was my dead body (lying) in the bed. (18)

The ability to observe in detail the movements of people and the location of objects within the external environment is one of the most perplexing problems raised by this stage. How can someone see when the senses seem inert? We have subjects who say they have verified movements and locations of people and identified objects they could not have known were present.

There are, however, cases where perception has been quite inaccurate. The subject may perceive objects and people not present. The following is from a woman who "died" while undergoing a ruptured tubal pregnancy:

The one thing that I was aware of, I saw this little table over the operating table. You know, those little round trays like in a dental office where they have their instruments and all? I saw a little tray like that with a letter on it addressed (from a relative by marriage whom she had not met). (38)

She later told this story to her sister-in-law, a registered nurse, who had been called into the operating room during the crisis. The sisterin-law told the woman the round tray and letter were not in the room. Interestingly, the letter on the table was from the nurse's brother-in-law.

I don't know whether it was her presence I was sensing or if someone in the conversation (in the operating room) mentioned her name. (38)

The tray to which she refers is probably not a round, dentist tray but the small, rectangular instrument table called a Mayo. The tray can be pulled over a surgical table. Notice it sounds like "mail". She may have heard someone call the tray by name (since hearing is reportedly the final sense to fail at death) and connected it with "mail."

In another example of misperception in the second stage, two 
people were involved in a serious car accident:

Well, then I remember, not physical bodies but like holding hands, the two of us, up above the trees. It was a cloudy day, a little bit of clouds. And thinking here we go, we're going off into eternity ... and then bingo, I snapped my eyes open and I looked over and he was staring at me. (49)

In this incident a woman had lost consciousness but her male companion had not. In the experience, she perceived the two of them in an out-of-body state, yet her friend never blacked out. He had, however, received a hard blow on the head. He could not confirm her perception. Monroe (1971) has written about this problem:

One problem is encountered periodically in perception during the Second State. It may be more common in perception by physical means than has been reported, and thus not unique. I refer to the question of the mind's identification of persons, places and things which up to that moment have been unknown and unperceived previously.

In the quest for evidential data and self-orientation, the mind seems to act strongly in response to an unformed thought command to "Identify!" without modification or equivocation. There fore, when an unknown or apparently impossible situation, place, person, or thing is encountered, the mind comes up with some kind of answer rather than no answer whatsoever.

The answer takes the form of rationalization, if it can be called that; or more commonly, a search is made of past memories and experiences to produce proper identification. It compares the situation under which the object or action is perceived with past personal experience. If there is nothing to coincide exactly with the observed data, the mind invariably reports the most similar memory and states, "This is the object or action you are seeing." It is only after critical analysis that some semblance of what actually was perceived comes to light (p. 185).

Once again, our figures differ from those reported by Ring. Our sample had 39 of 55 encounters with death reach the second stage for a total of 70.9 percent. Ring reported only 37 percent of his respondents entered the body-separation phase.

Third Stage. In this stage some people find themselves moving through a void or blackness. They may also travel through a long tunnel. Apparently this is an intermediate stage as the awareness shifts from the external environment to the inner setting.

A man who had attempted suicide with an overdose of Miltown and Equanil described the blackness:

It was a void. It had no distance. (5)

From a woman who "died" of blood poisoning:

Soon as I left the room I was inside a black river. Everything was dark- 
ness. I was all alone and suffering terribly and the waves were washing me to and fro. A voice spoke behind me, a big voice. It sounded like it was through a megaphone ... and he said: "This is the river of death. This is the river of death. This is eternity. You're lost. This is eternity." (31)

The experience of moving through a tunnel is a distinct element of the NDE but has the same subjective purpose of transition as the darkness. A man who experienced a heart attack described the tunnel effect in this manner:

I felt like I was going up at about a 45 or 50 degree angle ... at the end of the tunnel, I say tunnel but I don't mean a tunnel like a tunnel. It was kind of like a funnel. (32)

Our percentages in this stage drop to 21 of 55 instances or 38.2 percent of the sample. Ring reported 23 percent of his respondents experienced this stage.

Fourth Stage. The experience of the third stage often leads directly into the fourth stage, "encountering the light." This light is almost inevitably described as brilliantly white or golden. However, there are exceptions. A French woman we interviewed described this light as pink and blue.

From a man who experienced a heart attack:

The more I concentrated on this source of light the more $I$ realized that it was a light of a very, very peculiar nature ... it was more than light. It was a grid of power . . . if you could imagine the finest kind of gossamer spider web that was somehow all pervading, that went everywhere. (27)

At this stage, religious preference and family background begin to have some effect on one's interpretation of the nature of the light. Many who had deep religious convictions said this light was God or that they had seen the figure of Christ within the light. Most people, including many who were quite religious, described the light as impersonal, though warm and compassionate.

The light that surrounded my hospital bed was so brilliant, I could actually see my bones!" (15)

The light was tremendously bright ... it was the destination. (16)

One woman (6) described the light as "very white" and like the glow of a Coleman lantern.

In our study respondents encountered the light in 31 of 55 encounters or 56.4 percent. Ring reported 16 percent for this stage.

Fifth Stage. The fewest near-death experiencers reach this stage, the "inner setting." In looking through the descriptions of the inner setting, it is apparent that this stage is referred to in different cul- 
tures by a variety of names. The "Realm of the Ancestors" in Hindu mythology, "The Happy Hunting Ground" (so called by the white culture) of the Plains Indians, and "paradise" in Judeo-Christian and Islamic cultures. This is where consciousness finds itself before resuscitation takes place.

One description of this state was given to us by a woman thirtyeight who had nearly drowned when she was eight:

I was in a garden, right behind a bush but I could see everyone that was ahead of me. In the garden there was this one, big, large tree and there were children playing a game; there was seven children; and I saw a bunch of flowers, there was a butterfly and a deer next to me who I felt lick my face. At the time, I didn't understand that but I was more curious about what was going on beyond me. The children saw me and they beckoned me to come over. And I hesitated but when I finally decided to step over ... then I felt this heavy tug, like a vacuum and then I was forced out and the next thing I knew I was back in my own body. (40)

This incident is interesting for two reasons. It demonstrates the almost playful nature of consciousness at the moment of death. The seven children were playing ring-around-the-rosey.

Ring around the rosey

pocket full of posey.

Hush-a! Hush-a!

All fall down!

One suspects that if she had heard the last words of this stanza she would not have found herself back in her body. The line "All fall down" is a poignant metaphor of the child sinking into death.

The natural setting of this episode also contains mythological symbols which often appear in the inner setting. From a drawing of the scene provided by the respondent, the following points were evident: First, a tree in the center of the garden is certainly reminiscent of the "Tree of Life" found in many cultures: Judeo-Christian, Hindu, and Native American. Second, a path that winds its way through the garden is also a universal symbol of the journey through life. The reasons for the appearance of these symbols in far-flung cultures is widely debated. Perhaps a closer examination of the inner setting might contribute to our understanding of the dispersion of mythological symbols throughout the world.

Our respondents reported reaching this stage in 19 of 55 encounters for a total of 34.5 percent. Ring reported 10 percent of his subjects experienced the fifth stage.

Non-Experiencers. Only 5 of the 55 encounters with death produced no near-death-type experience. One non-experiencer had "died" on a previous occasion and had a classic near-death experi- 
ence. The other four respondents were either heavily drugged or had been under anesthesia for a period of twelve hours at the time of clinical death. These factors seem to support Ring's contention that heavy drugs and previous experiences seem to inhibit the near-death experience. It is also worth noting that four of the five subjects were agnostic at the time.

We suspect our method of contacting individuals limited the number of non-experiencers we reached. We were careful not to mention that our research purpose was to examine the near-death experience. Although we also asked non-experiencers to contact us, it seems we were not successful.

Hellish and Negative Experiences. The primary emphasis in most of the near-death literature has been on the celestial aspects of the experience. Clearly, most reports are extremely positive in nature, but there are cases of negative and even "hellish" experiences.

We define a negative experience as one that contains extreme fear, panic, or anger. It may also contain visions of demonic creatures that threaten or taunt the subject. In the hellish experience the subject witnesses the proverbial fiery pit and sees "the devil himself."

Most negative experiences begin with a rush of fear and panic or with a vision of wrathful or fearful creatures. These are usually transformed, at some point, into a positive experience in which all negativity vanishes and the first stage of death (peacefulness) is achieved. It is also common for the negativity to come at the end of a more positive experience, suggesting the negativity lies in the transition from ordinary consciousness to the peace of the first stage. This may be the source of the mythological "fall from grace" reported in cultures throughout the world. One woman, who is religious, described the "fall from grace" thus:

As I was returning to my body, I had a feeling of coming to a very wicked world and it filled me momentarily with fear.

When I awoke, the realization of who I had seen (Christ) came to me, and what had happened. (29)

Another man, who experienced a cardiac arrest, reported viewing a demonic figure that taunted him, he felt, for being concerned only with "fun and games" during his life. This scene eventually resolved into a beautiful Stage Five setting where he conversed with his deceased father. (43) These examples demonstrate the transitoriness of the negative experience.

We located only one case involving hellfire and darnnation in our investigation. If one combines Moody's, Ring's, and The Evergreen Study, only 1 in a combined sample of 301 individuals (.3 percent) 
described a hellish experience. Note also that this man was reportedly ushered into hell by mistake on his second of three near-death experiences.

Respondent: The second experience was different, I went downstairs! Downstairs was dark, people were howling, (there was) fire, they wanted a drink of water... Then somebody came to me, I don't know who it was, he pushed me aside and said, "You're not coming down here. You're going back upstairs."

Interviewer: Did he actually use those words?

Respondent: Yeah. "You're going back upstairs. We don't want you down here because you're not mean enough."

Interviewer: Did you first experience the blackness and then ...

Respondent: Pitchblack. First we went down ... it was pitchblack.

Interviewer: Did you go down a tunnel?

Respondent: It was not a tunnel, more than a tunnel, a great big one. I was floating down .... there was a man there waiting, he says, "He's not the one.

Interviewer: Could you see the people that were yelling?

Respondent: I seen alot of people down there, screaming, howling ...

Interviewer: Were they also in clothes?

Respondent: No, no, no. No clothes at all.

Interviewer: They were nude?

Respondent: Yeah.

Interviewer: And there were how many would you guess?

Respondent: Oh, Christ, you can't count them.

Interviewer: Thousands?

Respondent: I'd say about, almost a million to me.

Interviewer: Oh, really? And they were all really miserable?

Respondent: They were miserable and hateful. They were asking me for water. They didn't have any water.

Interviewer: And there was a presence that was watching over them?

Respondent: Yes, he was there. He had his little horns on ...

Interviewer: He had horns on! Do ... who do you think ... . do you recognize this person?

Respondent: Oh yes. I know him anywhere.

Interviewer: Who was it?

Respondent: The devil himself! (35)

The interview continued with descriptions of the heat and fire of hell, the devil's disciples, and the time the respondent spent there (about four hours). Interestingly, this experience was sandwiched between two positive experiences. During the first episode the man spent time in "paradise." The second, hellish experience took place weeks after the first and shortly before the third and positive experience.

The incidence of a partially negative or hellish experience within a near-death encounter was 11 in 55 or 20 percent, with the remaining 80 percent either a positive experience or no experience at all. 
God, Guides, and The Decision to Return. Regardless of what stage an individual reaches, at some point he decides to return to life. This decision is the final event in the near-death experience and is accompanied by a rapid, usually instantaneous, return to the proper body. The experiencer usually does not pass through a tunnel on the trip back to his body. In only three cases was there even an awareness of time passing between the decision and the return. And all of these subjects commented that they returned much quicker than they left. Our findings here strongly support Ring's (1980) data on the decisional process in near-death experiences.

The decision to return may be voluntary: people report having unfinished business "back on earth" and so they return. Women report especially the desire to finish raising children. In fact, some characterize returning for the sake of their children as their "mission."

Often, however, the decision to return is not voluntary. Many report fighting the return to their bodies. Upon regaining consciousness, they may be angry and resentful of having to return to a body racked with pain. Evidently, getting back into the body is an unpleasant sensation comparable to "getting in to a peapod ... almost a moist shell." (2)

Strangely, the decision to return may involve a period of confusion and bargaining between the experiencer, the guide, and "God Himself." The man who was misrouted to hell is an example of what seems like inefficiency in the operation of the afterlife.

A subject of ours related a remarkable experience in which he was led by his guide, "Joe," into a dark waiting room. From there he listened to Joe conferring with other presences on what they should do with him:

I could hear some other people talking, or the presences, whatever you want to call them, off on the other side of the door about what they should do; whether they should send me back, whether I should go back. They consulted each other about what my age was, my youth, and I felt they were really discussing my future. For a long time I felt I could remember what they said in there but anyhow, the upshot of it was, that it was decided that, yes, I would go back but Joe would go with me and he was supposed to take care of whatever problems presented itself. (16)

The problem this man refers to was the removal of a portion of his right frontal lobe. Between the accident and recovery, he was hustled back and forth between the room and body on four separate occasions. Eventually, the decision to return was made and Joe returned with him to serve as a guide to his damaged brain. This relationship was benevolent for a number of years until Joe began making attempts to take "possession" of the man's vocal chords. A struggle 
ensued in which his brother choked him by the neck while he "killed" Joe internally . . . and that was the dramatic end of Joe.

It is not uncommon for the experiencer to consult the guides regarding the advisability of returning to the body. The individual weighs what he has accomplished in his life and determines whether to continue his "mission" on earth or remain with the guides. A woman who was involved in a serious car accident was told by her guides:

You have more time on earth, if you want, you have a choice... but before you make that decision I want to show you something; and so they proceeded to show me my life ahead into the future ... he said, "Remember if you check out now, you'll just have to come back and finish your mission. But it's up to you, you have free will." (21)

The future they showed her involved many personal things which, she reports, have come true. At any rate, she bargained for an undamaged body to return to, stating she would not return to a body that was not completely healed.

In a similar occurrence, a man who was accidentally electrocuted said this:

The next thing I remember, there was a cloud and a male, related to Jesus, 'cause he looked like the pictures of Jesus. He was in this chariot type ... the torso was a horse, everything above the torso was a man with wings; sort of like a Pegasus except instead of a horse's head it was a man ... and he was beckoning to me ... and I kept backing up ... I remember telling him no, I had too many things to do and there was no way I could go now. Then the clouds sort of filled over and as it filled over I heard Him say, "O.K.!" (44)

Occasionally, the guides function as a tribunal that reviews the individual in a more formal manner. The person approaches them as one would a panel of judges, with respect and some trepidation. The tribunal experience was reported to us in 5 of 55 encounters with death ( 9 percent). Two of the five cases involved brothers who had near-death experiences ten years apart. They told us that neither had discussed the matter with the other for almost twenty years because of a fear of ridicule. Such cases deserve close attention because of the shared family background, which may shape the experiences. A second point of interest is that the content of both seems to support Ring's contention that the near-death experience is an encounter with one's higher self.

The first brother was undergoing a spinal fusion operation at the time of his experience. In it, he found himself before a group of shadowy figures who asked him the following:

. . explain in four words what my life was all about. Of course, I 
immediately started thinking about love and all this stuff ... so they told me the answer and I couldn't believe it! It was so simple, that life was explainable in four little words. (10)

The message was so disturbing to him that - he reported - he leaped from the operating table with the surgical knife stuck in his back and ran down the hall! Later, he awoke "roaring like a bull" and bent the frame of his hospital bed. "I was really powerful," he said.

He spent the following $5 \frac{1}{2}$ months recuperating and trying to remember the phrase, which had been blanked from his memory.

I've kind of pieced it together through the years. The closest I can come and have any satisfaction with is "In your own image." In other words, you're an individual living by yourself, for yourself, and with yourself, and there's nobody like you. (10)

His brother had a remarkably similar experience in terms of the tribunal review and realization of the nature of the "Self." In his experience he stood before a tribunal (at a location he later journeyed to and recognized as being the Parthenon in Greece):

While I was up in front of this guy that asked me this question there was a whole troop of guys off to one side ... come to look at them, they were all me, I guess, at different times. One was dressed something that looked like a pirate, another one was in robes like an old Greek philosopher or something. Another one, way older, maybe thousands of years older, looked like; very crude clothing; looked like a shepherd or something. And then I noticed sort of a medieval green outfit like they were in England in the time of Robin Hood. There was about three young guys almost all the same age; 21 to 23 . Then I realized that those were lives that I had lived before! And it took me three lives to get through this situation in old time England. (11)

The Life Review. Only five people (9 percent) reported experiencing the panoramic life review. The mode of death in each case was accidental except for a young man who, with no history of heart trouble, experienced a heart attack. This coincides with Ring's view that it is the suddenness or unexpectedness of death that brings on the life review.

Three of our subjects related a selective, partial review of scenes from their lives. The remaining two had complete life reviews in which they observed visual imagery of their early childhood to the present. The scenes were replayed in a patterned, sequential display from the earliest memories to the most recent.

Gender \& Mode of Death Relationship to the Near-Death Experience. Roughly two-thirds (62 percent) of those who related a neardeath experience were women. Of 55 encounters with death, 50 near-death experiences were reported. The following table illustrates 
the gender and mode of death relationship to the near-death experience. We define accidental death as that which occurs unexpectedly through carelessness or by chance, including electrocution, homorrhaging, reaction to drugs and anesthesia, etc.

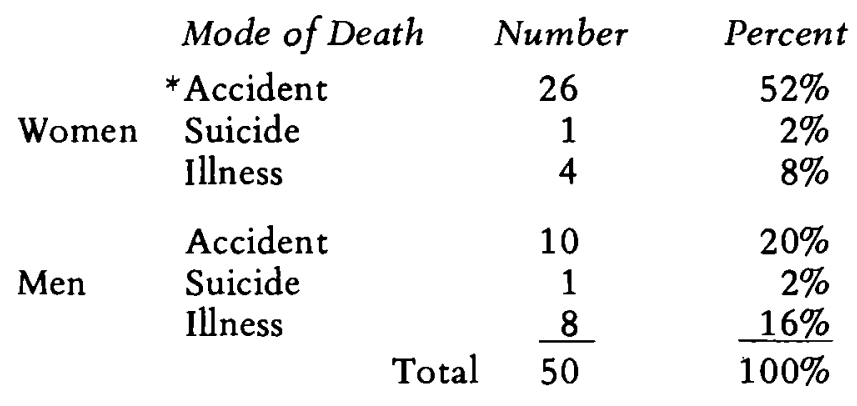

( 5 non-experiencers not included)

*women had a high number of near-deaths by hemorrhaging.

Demographics. Our demographic information was incomplete. However, we noted apparent minor differences between our study and Ring's in the areas of race, religious preference, and gender. We suspect these variations are due, however, merely to regional differences between the Pacific northwest and New England. We had a higher proportion of non-religious and Protestant respondents than Ring. The Pacific northwest is predominantly Protestant while New England has a higher percentage of Catholics. All of our respondents were Caucasian but the population of Washington is only 3 percent black. Also, there was a difference in how we contacted people. Ring received many of his contacts through hospitals while we reached most of ours through advertisement. We believe women were more likely to answer an advertisement and share a personal experience with us than men.

Life Changes as the Result of the Near-Death Experience. The most frequently mentioned result of the near-death experience is a shift to a more positive view of life. The person generally becomes more appreciative, compassionate, and spiritual. This increase in spirituality does not necessarily mean an increase in a conventional acceptance of religion. These findings are consistent with Ring's on after effects.

There is a tendency for the initial euphoria to fade in time although the memory of the event remains clear. A woman described having the patience of a saint for about a month following her episode. After that she became more normal. The ineffable feelings 
of the experience also tend to fade, although the memory remains fresh.

Essentially, we found the experience to have a profound effect on the values and internal perceptions of the individual, but the emotional impact tended to fade with the passage of time.

\section{DISCUSSION}

Our main concern has simply been to collect data and not be bound by the assumptions and interpretations suggested by some researchers and experiencers. Our desire has been to examine the neardeath phenomenon in terms of established psycho-biological principles without succumbing to the temptation to quash certain features of it that challenge our preconceptions of life and death. Clear$\mathrm{ly}$, this phenomenon deserves the most rigorous examination possible because it seems to be more common than had previously been realized.

The first stage of death is possibly the most easily explained from a biological point of view. The peacefulness of this phase could be due simply to the act of dying itself. Death is terminal relaxation. Assuming there is a subtle degree of awareness left in spite of our definition of clinical death, the brain may interpret this state of relaxation as peace, bliss, or freedom. It might be compared to the sensation of climbing into a warm bath in which there is an immediate relaxation of muscles and the feeling "aaahhh!" A second factor in the blissfulness of this stage might be the group of endogenous morphine-like substances called endorphins. That endorphins are involved in pain mechanisms has been firmly established. There is also increasing evidence that links these morphinelike substances to the placebo effect (Fields, 1980) and to the anelgesic properties of acupuncture (Chen, 1976). Beyond this narrow inhibitory function there is also the intriguing discovery that endorphins are found in areas associated with emotional responses and hormone control (Goldstein, 1976) and may be an evolutionary complement to the "fight or flight" reaction (Akil, 1976).

Prior to death, many subjects interviewed reported being in a state of anxiety and pain comparable to the fight-or-flight reaction. This was followed by a sudden cessation of pain and anxiety and the commencement of ineffable sensations of peace and well-being at the moment of clinical death. It seems plausible that physical stress disrupts homeostasis, triggering a massive release of endorphins and enkephalins, possibly from the brain's central core. This release of endorphins could then produce the reported feelings of peace and 
well-being that characterize the first stage of the near-death experience.

There are relatively high concentrations of endorphins located in the hypothalamus (Van Vugt and Meites, 1980). A review of this structure will illustrate the role it may play in providing a mechanism for Stage One of the near-death experience.

The hypothalamus is located above the brain stem in the central core of the brain. In spite of its relatively small size, it plays a major role in many functions. Certain areas of the hypothalamus monitor body temperature, maintain homeostasis, and apparently control endocrine functions. The hypothalamus appears to direct the body's reaction to fear and stress by stimulating it to return to the level of functioning prior to the disruption of equilibrium.

In emotion, the hypothalamus also serves a function. When certain areas are stimulated by electrodes, feelings of pleasure arise. If nearby portions are stimulated, however, there is an unpleasant and even painful sensation. Specific areas of the limbic system have also been stimulated in the course of neurosurgery with similar responses of pleasure, anxiety, or fear. Generally, the patient is awake during the operation and experiences difficulty in describing the pleasurable sensations with accuracy (Vander et al, 1980). It seems probable that the affective component from the electrical stimulation has a neurochemical basis and that the analgesia associated with stimulation is produced by the release of endorphins (Marx, 1977).

Is there a link between the sense of well-being of Stage One of the near-death experience and the endogenous opiates? From hundreds of interviews with near-death experiencers it is well documented that a sudden cessation of pain and anxiety occurs as the body systems fail. Most experiencers describe entering a state of unequalled peace and contentment, which continued to increase the longer they remain unrevived. Upon resuscitation, most subjects report a rapid return to the previous state of pain coupled with a longing for the ephemeral peace they had found in "death." Other experiencers report that the euphoria continues for an undetermined amount of time after revival but that these sensations eventually fade, leaving a powerful memory of the event.

If endorphins are involved in the near-death experience, they must be capable of acting very quickly to account for the rapid cessation of pain characteristic of Stage One. Like some other neurotransmitters, enkephalins have a rapid onset and offset of action (Klee, 1976). Maximum analgesia is reached in two minutes followed by rapid enzymatic degradation within five to ten minutes. The experimentally defined properties of enkephalins seem to correlate with subjective reports of most near-death experiencers. Those who report 
a longer lasting euphoria may possibly be experiencing the effects of the beta-endorphins, which are more stable and less easily metabolized. Note also the time frame within which the release and dissipation of enkephalins occur. It would encompass the period from death to revival of most experiencers and would account for the rapid onset and offset of Stage One.

The "cue" for the release of the endorphins/enkephalins may originate within the hypothalamus as a response to the unprecedented disturbance of equilibrium brought about by the onset of death. As the simultaneous failures of heartbeat, respiration, and other vital functions occur, the hypothalamus may make a final attempt to restore homeostasis to the internal environment by triggering a massive release of endorphins/enkephalins within the brain.

From an evolutionary perspective, this response can also be viewed as an adjunct of the fight-or-flight reaction. An animal whose death seems imminent must have a system that will. suppress pain and initiate the euphoria necessary to act defensively. We hypothesize that the mechanism that prevents incapacitation in life-threatening situations involves this group of endogenous morphine-like substances.

Ring has observed that the incidence of a near-death experience can be affected by the presence of drugs within the body at the time of death. Although this has not been fully established, some drugs may inhibit the experience of Stage One while other drugs and alcohol have no effect. An explanation might be that certain drugs block the endorphins/enkephalins, which are themselves suspected of being neurotransmitters (Vander et al, 1980).

Ring also contends that subjects who have had a previous NDE or even knowledge of near-death experiences tend to have a less intense experience or no experience at all. Although we did not fully corroborate this, it would still not fall outside of the endorphin/enkephalin hypothesis. Most experiencers report having a complete lack of fear of death following the near-death experience. In fact, many look forward to death. This could prove to be antagonistic toward a fight-or-flight reaction and subsequent release of endorphins/enkephalins if the manner of death is not too violent or unexpected. In a naturally occurring death, an experiencer would meet his fate with the powerful memory of Stage One and would be less likely to experience panic associated with "fight or flight."

It has also been observed that terminally-ill patients often enter a period of remission before dying. This phase, which may last for several days, is frequently described as a state of peace, contentment, and relative painlessness. If this final stage of dying is but a qualitative degree below the euphoria of the first stage of death, one would 
expect that endorphins are providing the analgesia. In that event, an injection of naloxone (a pure narcotic antagonist) would dramatically reduce the feelings of contentment and painlessness of the remission period. The return to pain would be short-lived and the subject would quickly recover his comfort. Such a test raises obvious ethical questions but is suggested to stimulate thinking along these lines. This or a similar test might indicate whether endorphins are involved in the last stage of dying. By implication, one would then suspect a similar analgesic effect occurring in Stage One of the near-death experience.

We confess, at this point, being unaware of convincing biological explanations for the succeeding stages. It is possible the out-of-body experience is a "programmed"' behavior to preserve essential identity" by appearing to separate consciousness from the threatened physical body. Computers are programmed to react in this way to preserve "essential information" in the event of a complete breakdown of the system. Perhaps the body has a similar mechanism. This is only a partial answer though, and doesn't begin to explain the perception of external and internal environments that accompany this and succeeding stages, especially those that involve veridical perceptions while out-of-body (Sabom, 1981). For this reason, we are eager for neuroscientific researchers to come forward and confront the challenge of explaining the near-death experience as a whole.

We have given a great deal of emphasis in the Results portion to personal descriptions of the inner setting, the light, and so on. In examining the mechanisms of the experience, it is important not to discard the subjective reports of our respondents. Practically all report these experiences as real and in the most emphatic terms. In fact, a sizable portion regard the near-death experience to be more real than their normal perceptions of reality. Although some researchers might find this difficult to believe, it is important to remain open at this point to the possibility that there is some truth in the perceptions of these sane, responsible people.

\section{SUMMARY}

The near-death experience clearly has invariant characteristics. It occurs in significant numbers of people who have experienced clinical death. These reports come from individuals of widely dispersed groups and a variety of social and religious backgrounds. Near-death experiencers report reaching at least one of the five stages of neardeath: Stage One, feelings of peace, freedom, and well-being; Stage Two, the sensation of separation from the body; Stage Three, the 
tunnel effect, or entering the darkness; Stage Four, encountering the light; Stage Five, the inner setting. Each of these stages is marked by extraordinary but patterned phenomena.

Feelings of peace and well-being are possibly due to the " terminal relaxation" of dying and to the effects of endorphins. The concept of clinical death needs to be reexamined in light of the reports that consciousness continues even after prolonged periods of apparent death.

The near-death experience is a subjective and highly personal exploration of an inner state. Although we may expound theories regarding the nature of this phenomenon, the experience of death stands as an existential reality outside the present limits of empirical knowledge. Regardless of whether the experience is "real" or hallucinatory, it very definitely and profoundly changes the life of a near-death survivor.

\section{REFERENCES}

Akil, H., Madden, J., Patrick, R. L., and Barchas, J. D. Stress-induced increase in endogenous opiate peptides: concurrent analgesia and its partial reversal by naloxone. In $\mathrm{H}$. W. Kosterlitz (Ed.), Opiates and Endogenous Opioid Peptides. Amsterdam, New York: North Holland Publishing Co., 1976, 63-70.

Chen, G. S. Enkephalin, Drug addiction and acupuncture. American Journal of Chinese Medicine, 1977, 5 (1), 25-30.

Fields, H. L. Secrets of the placebo. Psychology Today, 1978, November.

Goldstein, A. Opioid peptides (Endorphins) in Pituitary and Brain. Science, 1976, 193.

Klee, W. A., Lampert, A., and Nirenberg, M. Dual regulation of Adenylate Cyclase by endogenous opiate peptides. In H. W. Kosterlitz (Ed.), Opiates and Endogenous Opioid Peptides. Amsterdam, New York: Noth Holland Publishing Co., 1976, 153-159.

Marx, J. L. Analgesia: how the body inhibits pain perception. Science, 1977, 195.

Monroe, R. Journeys Out of the Body. New York: Doubleday, 1971. Moody, R. A., Jr. Life After Life. Atlanta: Mockingbird Books, 1975. Ring, K. Life at Death. New York: Coward, McCann \& Geoghegan, 1980 . 
Sabom, M. B. The near-death experience: myth or reality? A methodological approach. Anabiosis, 1981, 1 (1), 44-56.

Vander, A. J., Sherman, J. H., and Luciano, D. S. Human Physiology: The Mechanisms of Body Function. New York: McGraw-Hill, 1980.

Van Vugt, D., and Meites, J. Influence of endogenous opiates on anterior pituitary function. Federation Proceedings, 1980, 39 (8).

Requests for reprints to:

James H. Lindley

1625 Groves Ave.

Olympia, Washington 98502 